\title{
Teachers' Nonverbal Behavior and Its Impact on Student Achievement
}

\author{
Noureen Asghar Chaudhry ${ }^{1} \&$ Manzoor Arif ${ }^{1}$ \\ ${ }^{1}$ International Islamic University Islamabad, Pakistan \\ Correspondence: Noureen Asghar Chaudhry, International Islamic University, Islamabad, Pakistan. E-mail: \\ noureen.asghar@hotmail.com
}

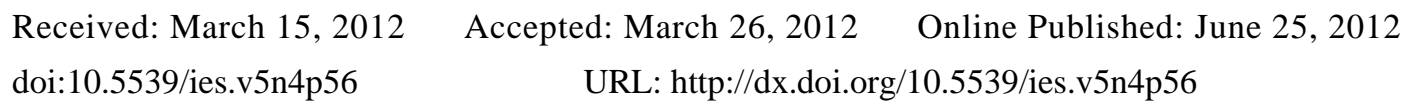

\begin{abstract}
The observational study was conducted to see the impact of teachers' nonverbal behavior on academic achievement of learners. This also investigated the relationship of nonverbal communication of teachers working in different educational institutions. Main objectives of study were to measure nonverbal behavior of teachers' both male and female working in English medium Federal Government Cantt Garrison schools, Army Public schools and Private schools and to find out the relationship between teachers' nonverbal behavior and academic achievement of students. 90 science teachers were randomly chosen through cluster sampling technique. An observation form with seven-point rating scale (semantic differential) based on Galloways' categories of nonverbal communication was developed. The rating scale complemented verbal dimension of Flanders' interaction categories through nonverbal dimension. Design of research was descriptive cum observational. The statistical techniques of frequency distribution, mean, standard deviation, and ANNOVA and t-test were used for analysis. The results were generalized to the population by means of appropriate inferential statistics. It was found that the nonverbal behavior of the teachers was found to be consistent with their verbal behavior.
\end{abstract}

Keywords: nonverbal communication, teacher, student, relationship, behavior, learning, mean, standard deviation, standard error of mean and population mean of teachers

\section{Introduction}

Nonverbal communication is the unspoken communication that goes on in every face to face encounter with another human being. It tells us their true feelings towards us and how well are our words being received. Nonverbal communication remains the neglected part of teaching learning system particularly in Pakistan. By neglecting it, effective communication in the classroom is not possible which is considered essential for better understanding of classroom instructions.

In the process of education Teaching is an important factor and is done by the teachers. Effective teaching is where teacher transfers subject matter to the students effectively. The most comprehensive review of elements of teaching effectiveness was completed by Walberg (1967), using the techniques of statistical meta-analysis, he compiled more than 3,000 studies, compiled a list of weighted factors which included engaged academic learning time, positive reinforcement utilization and cues including the feedback, co-operative learning activities, classroom atmosphere, morale, higher order questioning, and use of advance organizers. To understand how these factors fit together more clearly, Flanders (1970) clustered teacher's talking behavior into seven categories (and student's talk into two). These categories represent the most commonly observed teaching behaviors. The system of instruction proposed by Flanders not only ties seven teaching techniques into a well-knit system but it also serves as a 'bridge' between the specific teaching skills and general teaching models.

Studies have shown that teachers who have positive attitudes toward the world actually employ an important set of facilitating nonverbal cues to encourage student participation and involvement. Those with negative attitudes display nonverbal behavior designed to discourage and inhibit student involvement (Smith, 1981). Researchers could predict what type of nonverbal behavior a teacher would use if they knew the teacher's attitude set. Galloway and his colleagues (1977) developed non-verbal version of Flanders' system of instructional analysis that serves a useful frame work for analyzing teacher's nonverbal behavior. Few studies appear to have been conducted in Pakistan to investigate nonverbal behavior of teachers so as to verify its impact on students' learning. The results of research in this vital area of interest may generate useful knowledge about present status 
of teachers in this pedagogically important aspect that may serve as a valuable input for teacher education programmes, especially during teaching practice.

However, to an ironic degree, nonverbal aspects of teaching are overlooked, though 75 to 90 percent of messages are transmitted nonverbally. As a matter of fact, words turn out to be far less important than tone of voice, face expressions, eye contact, gestures and posture of the teacher as they are strongly associated with speech information which is being imparted to students. The real meaning of the words is conveyed in the way they are actually expressed or presented. In other words, medium becomes the message. Effective teachers, like good artists, use body language and facilitate their verbal behavior, leading to better understanding and learning of the subject matter by the students. (Sprinthall, 1994).

Verbal communication itself does not create that impact upon students' minds and hearts as does the non-verbal communication that complements the verbal message. Same verbal message may create opposite meaning and interpretation by students, the way the message is communicated through the medium of non-verbal communication.

Although both the frameworks are quite old but these served as a base for the ongoing research. Flanders' work is based on direct instruction or teacher centered instructions. In the educational system of Pakistan, instruction is still based on traditional method i.e, teacher centred. In such a situation, it becomes important to utilize the research work of Galloway to see how effectively nonverbal behavior of the teacher is involved in the system.

Similarly, Kodakos \& Polemikos (2002) conducted an experimental study on nonverbal communication at kindergarten level just to observe nonverbal relation of the teacher and children and most importantly its relationship to their verbal behavior.

Learning is a central focus of educational psychology. In the words of Santrock (2006), learning is a relatively permanent influence on behavior, knowledge and thinking skills, which comes about through experiences.

Another research by Alberts (2006) was conducted on the nearness or nonverbal immediacy within the classroom environment with the objective of finding a relationship between nonverbal communication usage and the keenness of the audience participating in discussion. A premise was made indicating that the students' keenness to discuss things with a teacher within the classroom environment actually helps them improve their performance and understanding.

Galloway's work is still important frame work for description of nonverbal behavior. In Pakistan also nonverbal communication is making its place in teacher centered instruction. Much current instruction in Pakistan is direct teaching. Although there is a paradigm shift and a movement away from direct teaching to instruction and inquiry based instruction. Teacher centered nonverbal intention is still important.

While analyzing effective teaching, more emphasis in teaching effectiveness was given to the verbal aspects of teacher behavior. This is supported by Sprinthall and Sprinthall (1994) who remarked that teaching practice and research on teaching effectiveness mainly focused on analysis and improvement of verbal behavior of teachers.

\section{Statement of the Problem}

The statement of the problem is to "Investigate and explore the existing relationship between teachers' nonverbal behavior and the students' academic achievements".

\section{Objectives of the Study}

The objectives of the study were to identify, measure and compare non-verbal behavior of the teachers' both male and female working in Federal Government Cantt Garrison schools, Army public schools and Private schools, to find out the relationship between teachers' non-verbal behavior and students' academic achievement and draw recommendations for teachers to develop their nonverbal behavior compatible with their verbal behavior.

\section{Hypotheses}

Following were the research hypotheses of the study:

H1. There is significant relationship between teachers' mean nonverbal behavior scores and their students' achievement scores.

H2. There is significant difference between the mean non verbal behavior scores of teachers' serving in private and public sector.

H3. There is significant difference between mean nonverbal behavior scores of male and female teachers'. 
The above would be tested through following null hypotheses:-

H01. No significant relationship between teachers' nonverbal behavior scores and their students' achievement scores.

H02. No significant difference between the mean nonverbal behavior scores of teachers' serving in private and public sector.

H03. No significant difference between mean nonverbal behavior scores of male and female teachers'.

\section{Method and Procedure}

All the male and female English medium Secondary School Science teachers in the subject of Physics, Chemistry and Biology working in Federal Government Cantt Garisson Schools, Army Public Schools and Private Schools located in Rawalpindi constituted the population of this study. A Sample of 90 Science teachers' (45 male and 45 female) out of 450 Science teachers was chosen from 30 secondary level schools out of 54 secondary level schools by two phase cluster sampling.

Table 1. Breakdown of sample of 90 Science Teachers

\begin{tabular}{llllll}
\hline Name of Schools & & $\begin{array}{l}\text { No of } \\
\text { institutions }\end{array}$ & $\begin{array}{l}\text { No of Teachers per } \\
\text { school } \\
\text { Male }\end{array}$ & Female & $\begin{array}{l}\text { Total no of } \\
\text { teachers }\end{array}$ \\
\hline $\begin{array}{l}\text { Federal Government } \\
\text { Garrison schools (Male) }\end{array}$ & Cantt & 05 & 3 & - & 15 \\
$\begin{array}{l}\text { Federal Government } \\
\text { Garrison Schools (Female) }\end{array}$ & & & & & \\
Army Public Schools (Male) & 05 & - & 3 & 15 \\
Army Public Schools (Female) & 05 & 3 & - & 15 \\
Private schools (Male) & 05 & - & 3 & 15 \\
Private schools (Female) & 05 & 3 & - & 15 \\
Total & $\mathbf{3 0}$ & - & 3 & 15 \\
\hline
\end{tabular}

To observe how far teachers nonverbal behavior was compatible with their verbal behavior, a seven point Differential rating scale suggested by Galloway was used. The body language of the teachers was rated on the scale. The main nonverbal communication elements pattern was divided into two main areas. Nonverbal behavior that facilitates student learning and that constrict student learning.

The rating on the observation form is as follows:

$1 \& 2$. While accepting student's negative and positive feelings, in unthreatening manner praising or encouraging them, teacher's body language is

Consistent with words and demonstrates an appropriate range of feelings

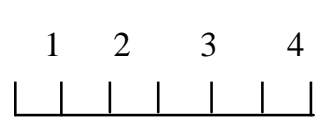

over controlled and feelings are rarely, if ever, shown

3. While accepting students' ideas, teacher's nonverbal are consistently

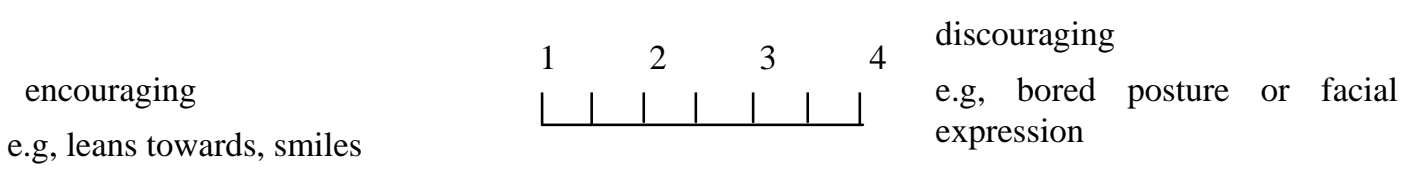


4. While asking questions, teacher maintains eye contact with the students

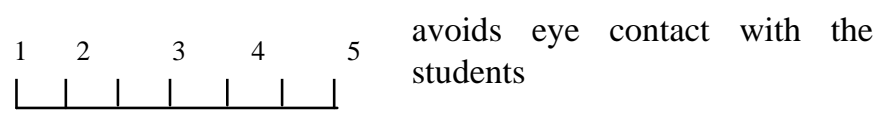

5. While lecturing;

teacher ensures variety in gestures, tone, pace of talk etc.

\begin{tabular}{|c|c|c|c|c|}
$1^{2}$ & 3 & 4 \\
\end{tabular}

teacher is monotonous, i.e drones on and on, with little variation in gestures, in tone and pace of talk etc.

6. While giving directions, teachers' nonverbal behavior body language encourages student's participation in clarifying directions

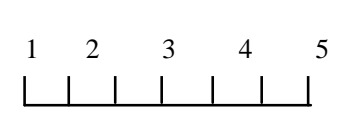

discourages participation participation student's i.e, to avoid

7. While criticizing, teacher's nonverbal behavior is firm and mild

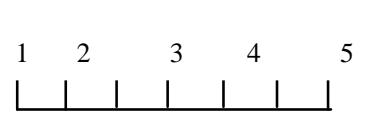

severe, aggressive and intimidating

The points on the rating scale represents the following:

1= Fully Consistent (Marks=7) $\quad 5=$ Moderately Inconsistent (Marks=3)

2=Highly Consistent $($ Marks=6)

6= Highly Inconsistent (Marks=2)

$3=$ Moderately Consistent (Marks $=5$ )

7= Fully Inconsistent (Marks=1)

4= Partially Consistent (Marks=4)

\section{Analysis and Interpretation of Data}

At this stage it is also worth mentioning that whilst the focus of the study was non-verbal behavior. The verbal behavior served as the context of nonverbal behavior. Mean, Standard Deviation, Standard Error of Mean and Population Mean of Teachers' Nonverbal Behavior Scores of the analysis are provided in the table below:

Table 2. Mean, Standard Deviation, Standard Error of Mean and Population Mean of Teachers' Nonverbal Behavior Scores

\begin{tabular}{lllll}
\hline & Sample mean & SD & SEm & $\begin{array}{l}\text { Confidence interval } \\
\text { of Population mean }\end{array}$ \\
\hline While accepting students' feelings & 5.6 & 0.8 & .08 & From 5.45 to 5.75 \\
While accepting students' ideas & 5.8 & 0.7 & .08 & From 5.66 to 5.94 \\
While asking questions & 6.3 & .71 & .07 & From 6.16 to 6.44 \\
While lecturing & 5.6 & .8 & .08 & From 5.45 to 5.75 \\
While giving directions & 5.9 & .8 & .08 & From 5.45 to 6.05 \\
While criticizing & 6.2 & .82 & .08 & From 6.05 to 6.35 \\
\hline
\end{tabular}

Table 2 above shows that, mean nonverbal behavior score of the teachers' was highly consistent with their verbal behavior. The nonverbal behavior was rated according to its consistency with teachers' verbal behavior. When Population Mean Score was inferred from the sample mean, the lower limit of the range of true mean again is interpreted as highly consistent (statistically) with their verbal behavior. 
Similarly the comparison between male and female teachers' nonverbal behavior was also carried out, the results are depicted below in table:

Table 3. Comparison between male and female nonverbal behavior scores

\begin{tabular}{|c|c|c|c|c|c|c|c|}
\hline & Group & $\mathrm{N}$ & Mean & SD & $\mathrm{SE}_{\mathrm{D}}$ & $\mathrm{t}$ & $\mathrm{P}$ \\
\hline \multirow[t]{3}{*}{$\begin{array}{l}\text { While accepting } \\
\text { students' feelings }\end{array}$} & Male & 45 & 5.6 & .8 & \multirow{3}{*}{.15} & \multirow{3}{*}{0} & \multirow{3}{*}{$>.05$} \\
\hline & & & & & & & \\
\hline & Female & 45 & 5.6 & .78 & & & \\
\hline \multirow[t]{3}{*}{$\begin{array}{l}\text { While accepting } \\
\text { students' ideas }\end{array}$} & Male & 45 & 5.7 & .9 & \multirow{3}{*}{.17} & \multirow{3}{*}{1.17} & \multirow{3}{*}{$>.05$} \\
\hline & & & & & & & \\
\hline & Female & 45 & 5.9 & .6 & & & \\
\hline \multirow[t]{3}{*}{$\begin{array}{l}\text { While asking } \\
\text { questions }\end{array}$} & Male & 45 & 6.3 & .6 & \multirow{3}{*}{.16} & \multirow{3}{*}{0} & \multirow{3}{*}{$>.05$} \\
\hline & & & & & & & \\
\hline & Female & 45 & 6.3 & .78 & & & \\
\hline \multirow[t]{3}{*}{ While lecturing } & Male & 45 & 5.8 & .9 & \multirow{3}{*}{.18} & \multirow{3}{*}{1.7} & \multirow{3}{*}{$>.05$} \\
\hline & & & & & & & \\
\hline & Female & 45 & 5.5 & .8 & & & \\
\hline \multirow[t]{3}{*}{$\begin{array}{l}\text { While giving } \\
\text { directions }\end{array}$} & Male & 45 & 5.8 & .9 & \multirow{3}{*}{.18} & \multirow{3}{*}{1.1} & \multirow{3}{*}{$>.05$} \\
\hline & & & & & & & \\
\hline & Female & 45 & 6 & .7 & & & \\
\hline \multirow[t]{3}{*}{ While criticizing } & Male & 45 & 6 & .9 & \multirow{3}{*}{.17} & \multirow{3}{*}{1.8} & \multirow{3}{*}{$>.05$} \\
\hline & & & & & & & \\
\hline & Female & 45 & 6.3 & .6 & & & \\
\hline
\end{tabular}

Table 3 shows that the obtained value of $t^{\prime}$ ' in each situation is less than the critical value (1.99) at .01 level of significance. Therefore, there is no significant difference between the mean non-verbal behavior scores of male and female teachers.

The comparison of nonverbal behavior scores of teachers working in private, FG Cantt Garrison and Army Public Schools was also conducted; the results obtained are appended below: 
Table 4. Comparison of Nonverbal Behavior Scores of Teachers Working in Private, FG Cantt garrison and Army Public Schools

\begin{tabular}{|c|c|c|c|c|c|c|}
\hline & Group & $\mathrm{N}$ & Mean & SD & $\begin{array}{l}\mathrm{F} \\
\text { Ratio }\end{array}$ & $\mathrm{P}$ \\
\hline \multirow[t]{3}{*}{$\begin{array}{l}\text { While accepting } \\
\text { students' feelings }\end{array}$} & Between & 1.7 & 2 & .85 & \multirow{3}{*}{1.39} & \multirow{3}{*}{$>.05$} \\
\hline & & & & & & \\
\hline & Within & 53.2 & 87 & .61 & & \\
\hline \multirow[t]{3}{*}{$\begin{array}{l}\text { While accepting } \\
\text { students' ideas }\end{array}$} & Between & 0 & 2 & .0 & \multirow{3}{*}{0} & \multirow{3}{*}{$>.05$} \\
\hline & & & & & & \\
\hline & Within & 48.4 & 87 & 0.6 & & \\
\hline \multirow[t]{3}{*}{$\begin{array}{l}\text { While asking } \\
\text { questions }\end{array}$} & Between & 1.1 & 2 & .6 & \multirow{3}{*}{1.0} & \multirow{3}{*}{$>.05$} \\
\hline & & & & & & \\
\hline & Within & 52 & 87 & .6 & & \\
\hline \multirow[t]{3}{*}{ While lecturing } & Between & 1 & 2 & .5 & \multirow{3}{*}{1.0} & \multirow{3}{*}{$>.05$} \\
\hline & & & & & & \\
\hline & Within & 59 & 87 & .8 & & \\
\hline \multirow{3}{*}{$\begin{array}{l}\text { While } \\
\text { directions }\end{array}$} & Between & 0.1 & 2 & 0.5 & \multirow{3}{*}{.07} & \multirow{3}{*}{$>.05$} \\
\hline & & & & & & \\
\hline & Within & 62 & 87 & .7 & & \\
\hline \multirow[t]{3}{*}{ While criticizing } & Between & 1.7 & 2 & .85 & \multirow{3}{*}{1.0} & \multirow{3}{*}{$>.05$} \\
\hline & & & & & & \\
\hline & Within & 60.1 & 87 & .7 & & \\
\hline
\end{tabular}

Table 4 shows that the obtained $\mathrm{F}$ value in each case is smaller than the value of $\mathrm{F}$ ratio required for significance at 0.05 level. It implies that no significant difference was found between nonverbal behavior scores of teachers working in Private, FG and Army Public schools. 
The correlation between teachers' nonverbal behavior scores and academic achievement of students is as shown below:

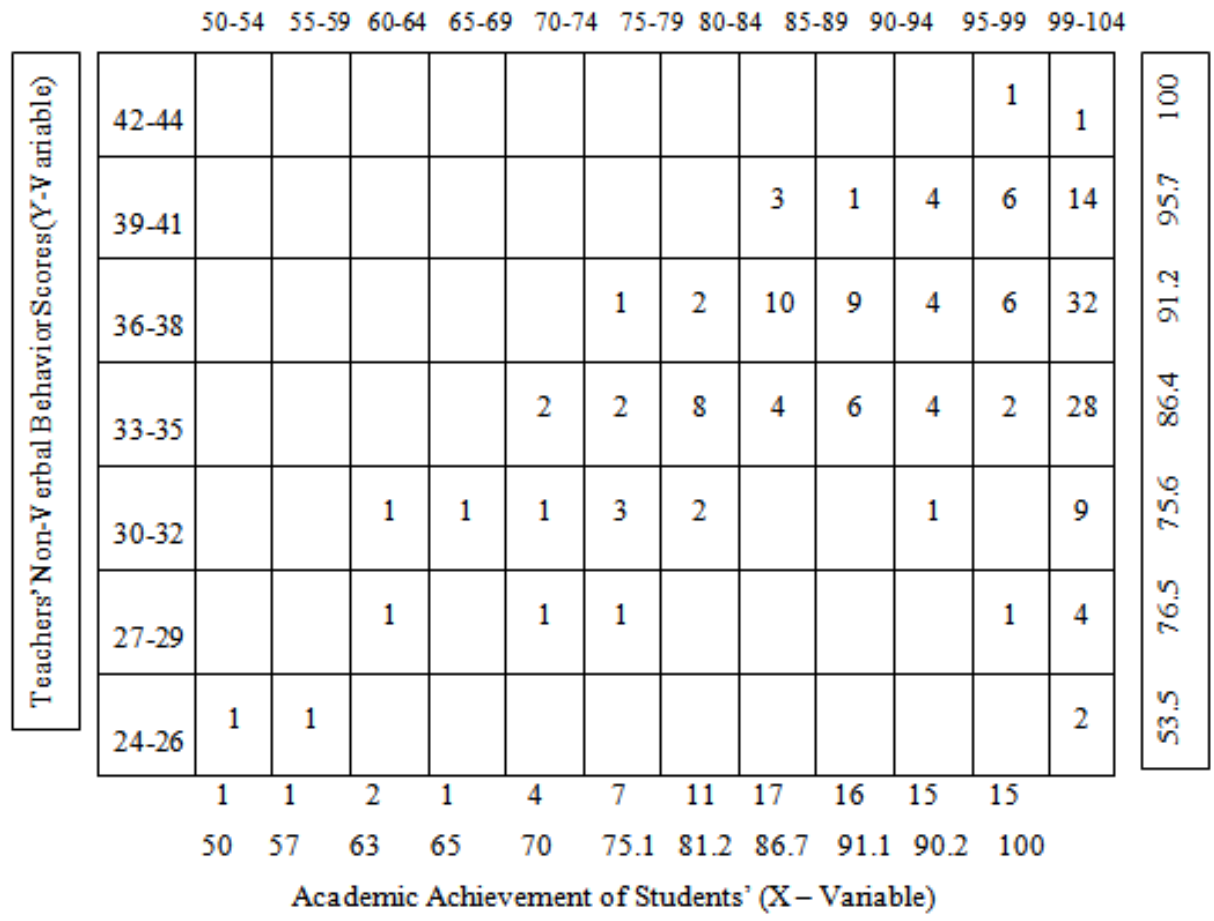

Figure 1.

The correlation table shows that, there is gradual increase in mean academic achievement scores and mean nonverbal behavior scores across columns and across rows of the table from left to right and bottom to top. This indicates that there is linear relationship between the variable of academic achievement of students and nonverbal behavior of teachers. Thus, the assumption of linear relationship is met for using the Pearson $r$ correlation technique.

The degree of relationship between nonverbal behavior scores of teachers and academic achievement scores of students evaluated as:

Table 5.

\begin{tabular}{lll}
\hline $\mathrm{R}$ & $\mathrm{PEr}$ & Strength of Relationship \\
\hline 0.7 & .03 & Strong \\
\hline
\end{tabular}

The above results shows that, value of $\mathrm{r}$ is much grater than $6 \mathrm{x} \mathrm{PEr}$, therefore it indicates strong positive relationship between nonverbal behavior scores of teachers and academic achievement of students.

\section{Conclusions}

On the basis of the findings of the study, it was concluded that Nonverbal behavior of the teachers was found to be highly consistent with their verbal behavior while accepting students' feelings, ideas, while asking questions, while lecturing, while giving directions, while criticizing. Male and Female teachers did not differ in their nonverbal behavior. Both male and female teachers praised and encouraged students action to avoid any tension in the class. Similarly, No difference was found between nonverbal behavior of teachers working in Private, Federal Government Cantt Garrison and Army Public schools. A Strong association was found between nonverbal behavior of teachers and academic achievement of their students. Careful directions, lecturing, and 
criticizing students for misbehavior, yet for the most part, employ questioning, reinforcing, cueing and responding to feelings produced academic gains to a better degree.

Research in many settings indicates that non verbal communication can serve a wide range of functions in human interaction. The results of the present study may help the teacher to supplement, reinforce, or regulate verbal messages with appropriate nonverbal messages.

\section{Discussion}

The research was based on Galloway's idea of non-verbal communication where the focus was only on non-verbal communication. It was a new topic to study in Pakistani system of education as no previous research work could be found on this topic in Pakistan. The research opened a new horizon in this area of human motivation for academic learning. One of the conclusions of the study was that nonverbal behavior of teachers was highly consistent with their verbal behavior. Another conclusion was that male and female teachers did not differ in their nonverbal behavior. This conclusion of the study has its own uniqueness. Furthermore, no difference between nonverbal behaviors of teachers working in different educational setups was found however, a strong association of non-verbal behavior of teachers and academic achievement of their students was observed. More insightful results could have been achieved through a supplementary focused verbal behavior study. Observation and video recording were used which was found to be the best technique to measure the non-verbal teaching behavior.

\section{Recommendations}

It is recommended that a curriculum of human communication be developed for teacher training programmes to make nonverbal behavior of teachers highly consistent with their verbal behavior. A policy for the teachers training covering maximum elements of non verbal communication should be developed and implemented. Nonverbal teaching behavior should be given central place in important techniques of teaching. As the research study showed no difference in the nonverbal behavior of male and female teachers, therefore both male and female teachers be made conscious of the intelligent use of their body language during teaching so as to make their body language more compatible with their verbal communication. As less research work appear to had been conducted on Galloway's framework, a variety of research studies be launched based on Galloway's framework of nonverbal communication e.g in order to explore effect of nonverbal behavior on student achievement experimental studies can be launched in which the experimental group may be exposed to specially trained teachers in nonverbal communication but the control group is exposed to routine teaching. Observation and recording being the tool used to see the impact of nonverbal communication, one way mirror recording techniques could be used for gaining better results. The instrument developed for present study can be used by the supervisory staff of teacher education institutions. However, in the light of Flanders and Galloways' system, an observational form be developed for the training and observation of teachers during teaching practice.

\section{References}

Albert, E. (2006). Nonverbal Immediacy in the Classroom. Retrieved from http://cronk@missouriwestern.edu (August 16, 2007)

Andrzejewski, C. E., \& Davis, H. A. (2007). Human Contact in the Classroom. Retrieved from http://www.sciencedirect.com (November 21, 2008)

Coulson M. (2004). Journal of Nonverbal Behavior. Retrieved from http://www.imi.aau.dk.com (Sep 18, 2011)

Cassell, J. (1999). Embodied Conversation: Integrating Face and Gesture into Automatic Spoken Dialogue System. Retrieved from http://www.media.mit.education.com (September 19, 2011)

Davis, H. A. (2002). Expectancy Value of Work Several Cognitive and Motivational Variables. Retrieved from http://eagle2.american.edu (December 10, 2008)

Ekman, P., \& Friesen, W. (2008). Universal Facial Expressions of Emotion: An Old Controversy and New Findings. Retrieved from http://www3.interscience.wiley.com (December 26, 2008)

Ekman, P. (1967). How Faces Share Feelings. Retrieved from http://www.nature.com (September 24, 2008)

Exline, R. V. (1971). Elements of Nonverbal Communication. Retrieved from http://www.nature.com (September 24, 2008)

Flanders, N. A. (1970). Analyzing Teaching Behavior Reading, Mass: Addison-Wesley, p.34

Galloway, C. M. (1977). 'Nonverbal'. Theory into practice, 16(3) 
Garrett, H. E. (2000). Statistics in Psychology and Education, $5^{\text {th }}$ Edition, S.T. Printers Rawalpindi, p.46, $191,217,405$

Gage, N. L. (1978). The scientific basis for the art of teaching. New York: Teachers college press

Galloway, C. M. (1972). Nonverbal Communication. Retrieved from http://www.jstor.org (August 8, 2008)

Gay, L.R. (1996). Educational Research, London: Prentice Hall, Inc. p.449, 493, 454

G M Steven. (2008), Education. Retrieved from http://www.books.google.com (September 17, 2011)

Haxby, J. M., \& Hoffman E.A (2002). Human Neural System for face Recognition and Social Communication. Retrieved from http://www.psy2.ucsd.education (September 20, 2011)

Hilgard, E. R., \& Spalding, K. (1977). Cognition, Behavior and Causality. Retrieved from http://www.sciencedirect.com (November 15, 2008)

Herring, R. (2011). California International Studies Project. Retrieved from http://books.Google.com (September 17, 2011)

Kodakos, A., \& Polemikos, N. (2000). Nonverbal communication in kindergarten. Retrieved from http://cronk@missouriwestern.edu

Parks, J.D., \& Others, (2007). Nonverbal Behaviors Used By Effective Teachers of At Risk African, American Male Middle School Students. Retrieved from http://citeseerx.ist.psu.edu (July 18, 2008)

Pearce, J. M. (2001). Transfer of Spatial Behavior Between Different Environments: Implications for Theories of Spatial Learning and for the Role of the Hippocampus in Spatial Learning. Retrieved from http://www.cardiff.ac.uk (November 18, 2008)

Rosa, S. B. (2002). Understanding The Role And Potential Impact of Nonverbal Communication In The Primary Inclusion Classroom. Retrieved from http://eric.ed.gov (December 25, 2008)

Santrock, J.W. (2006). Educational Psychology, second edition, Texas: Mc Graw Hill, p.210

Segerstrile, U., \& Monlar, P. (1997). Nonverbal Communication where nature meets culture. Retrieval from http://www.cognitivepsychologyarena.com (June 18, 2008)

Sidelinger, R.J., \& McCroskey, J.C. (1997). Communication Correlates of teacher clarity (Nonverbal Communication) in the College Classroom. Retrieved from http://eric.ed.gov (December 15, 2008)

Smith, A.H. (1981). Nonverbal communication in teaching. Review of Educational Research, 49(4), 631-672

Smith, A.H. (1988) Nonverbal Communication in Teaching. Retrieved from http://www.jstor.org (September 10, 2008)

Sprinthall, N.A. (1990). Educational Psychology, New York : Mc. Graw-Hill, Inc.

Staven, A. (1980) Role of Nonverbal Communication in Education. Retrieved from http://eric.ed.gov (December $10,2008)$

Vangelisti, A. L., \& Daly, J.A. (1999). Teaching Communication Theory Research and Methods. Retrieved from http://eric.ed.gov (June 25, 2008)

Walberg, H. J. (1990). Productive teaching and instruction, phi Delta, Kappan, 470-478. 